\title{
Specific Protein Kinase C Isoforms Are Required for Rod Photoreceptor Differentiation
}

\author{
Carolina Pinzon-Guzman, Samuel Shao-Min Zhang, and Colin J. Barnstable \\ Department of Neural and Behavioral Sciences, Pennsylvania State University College of Medicine, Hershey, Pennsylvania 17033-2255
}

\begin{abstract}
The protein kinase $\mathrm{C}(\mathrm{PKC})$ family of enzymes regulates cell physiology through phosphorylation of serine and threonine residues of many proteins in most cell types. Here we identify PKC- $\beta 1$ and PKC- $\gamma$ as isoforms that are essential for rod photoreceptor differentiation in mouse retinas. Using ex vivo retinal explants, we found that phorbol ester 12-myristate 13-acetate and insulin-like growth factor 1 (IGF1) induced rod differentiation, as defined by opsin or Crx expression, in a PKC-dependent manner days ahead of rod development in untreated explants. PKC- $\beta 1$ and PKC- $\gamma$ were colocalized with proliferating cell nuclear antigen (PCNA)- and STAT3-positive progenitors through the later differentiation period. Pharmacological or genetic inhibition of either isoform resulted in a partial reduction in the appearance of rods, whereas removing both isoforms resulted in their complete absence. Furthermore, a significant decline of STAT3 tyrosine phosphorylation was observed by activation of PKC, while inhibition of PKC resulted in an increase of phosphorylated STAT3 along with a delayed cell cycle exit of progenitors with prolonged PCNA expression. In adult retinas, IGF1 activates PI-3 kinase (PI3K), but in neonatal retinas its action is identical to the action of an PI3K inhibitor. These data unveil a novel signaling cascade that coordinates and regulates rod differentiation through specific PKC isoforms in mammals.
\end{abstract}

\section{Introduction}

Fate choices of neural progenitors are regulated through the actions of an integrated set of extrinsic and intrinsic factors. Like other regions of the CNS, the retina develops from multipotential sets of neuroblasts that give rise to specific cell types in a stereotypic sequence (Turner and Cepko, 1987; Holt et al., 1988; Wetts and Fraser, 1988; Rapaport et al., 2004). The retina develops in a general inner-to-outer sequence with rod photoreceptors among the last cell types to differentiate, predominantly during the early postnatal period (Young, 1985; Rapaport et al., 2004). Within the retinal epithelium, photoreceptor differentiation is influenced by a number of cell interactions mediated by either direct cell-cell contacts or through soluble factors released from cells (Watanabe and Raff, 1990, 1992; Altshuler and Cepko, 1992; Reh, 1992; Altshuler et al., 1993; Levine et al., 2000; Yang, 2004). Several factors have been shown to promote the formation of rods, but the mechanisms by which these signals regulate the transition from progenitor to postmitotic neuron are only partially understood.

In this study, we identify a pathway essential for rod formation that involves protein kinase C (PKC). The PKC family of serine/ threonine kinases consist of at least 10 isoforms that are grouped into three distinct classes: (1) calcium-dependent, or classical, PKCs (classical; $\alpha, \beta \mathrm{I}, \beta \mathrm{II}, \gamma$ ), (2) Ca independent PKCs (novel; $\delta$, $\varepsilon, \eta, \theta)$, and (3) atypical PKCs $(\lambda, \zeta, \iota)$ (Mellor and Parker, 1998).

Received May 24, 2011; revised Nov. 1, 2011; accepted Nov. 2, 2011.

Author contributions: C.P.-G., S.S.-M.Z., and C.J.B. designed research; C.P.-G. performed research; C.P.-G.,

S.S.-M.Z., and C.J.B. analyzed data; C.P.-G., S.S.-M.Z., and C.J.B. wrote the paper.

This work was supported by NIH Grant EY 013865 and the Macula Vision Foundation.

Correspondence should be addressed to Dr. Colin J. Barnstable, Neural and Behavioral Sciences, H109, Hershey

Medical Center, 500 University Drive, Hershey, PA 17033-2255. E-mail: cbarnstable@hmc.psu.edu.

DOI:10.1523/JNEUROSCI.2578-11.2011

Copyright $\odot 2011$ the authors $\quad 0270-6474 / 11 / 3118606-12 \$ 15.00 / 0$
In the mature nervous system, these kinases transduce signals involved in many different processes including ion fluxes, receptor modulation, cell proliferation, and gene expression (Kheifets and Mochly-Rosen, 2007). During development, specific PKCs have been reported to have a role in the fate specification of different tissues as well as the differentiation of several cell types. For example, primary cultures of hippocampal cells express the PKCs $\alpha, \beta$ I, $\gamma, \theta$, and $\zeta$ constitutively, while PKCs $\beta$ II, $\delta$, $\varepsilon$, and $\eta$ are upregulated upon the induction of differentiation with retinoic acid treatment (Oehrlein et al., 1998).

Here we specifically identify two PKC isoforms, PKC- $\beta 1$ and PKC- $\gamma$, that are pivotal for the development of rods, as their absence completely inhibits rod differentiation. We identified IGF1 as one specific activator of PKC- $\beta 1$ and PKC- $\gamma$ that can increase the number of rods differentiating from the retinal progenitor pool. One consequence of PKC activation is a reduction in phosphorylated STAT3, a molecule whose activation inhibits rods differentiation (Ozawa et al., 2004; Rhee et al., 2004; Zhang et al., 2004). We also found that at postnatal day 1 (P1), IGF1 binding activates its receptor, but the PI-3 kinase (PI3K) signaling differs between neonate and adult retinas. Overall, our results are consistent with the hypothesis that movement of retinal cells out of the progenitor pool into a rod photoreceptor differentiation pathway involves release of the differentiation block created by STAT3, and that this can be regulated in part by extrinsic factors such as IGF- 1 acting through PKC- $\beta$ I and PKC- $\gamma$.

\section{Materials and Methods}

Reagents Polyclonal antibodies against PKC- $\beta 1$, STAT3, pAkt1/2/3 (Ser 473) (Santa Cruz Biotechnology), pSTAT3 (Y705), PKC- $\alpha$ (Cell Signaling Technology), proliferating cell nuclear antigen (PCNA; Sigma), and PKC- $\gamma$ (Abcam) were used in these experiments. Antigen peptides for STAT3 were used for blocking reagents to check antibody 
A

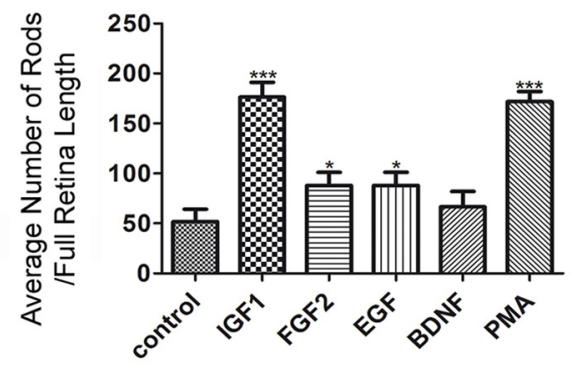

B

Control

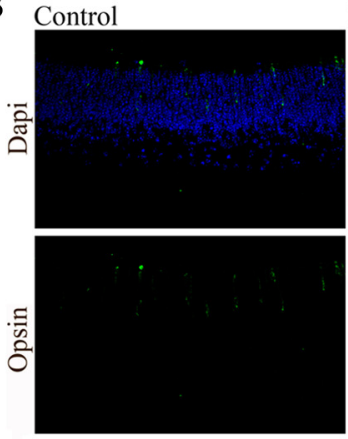

C

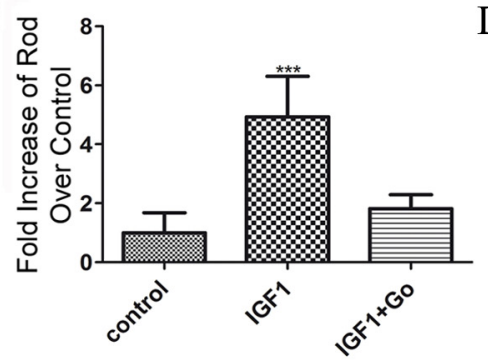

IGF1
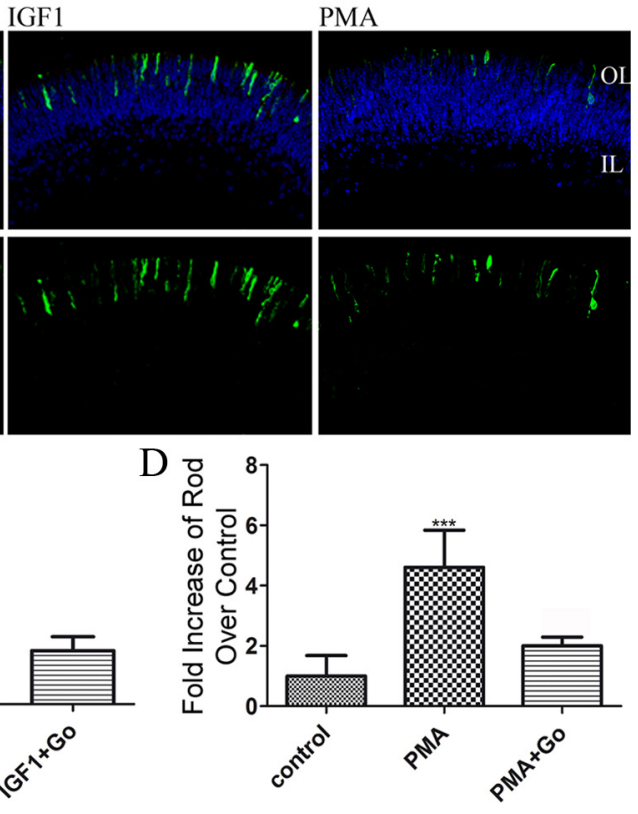

Figure 1. IGF1 and PMA increase the number of rod photoreceptors present in P1 retinal explants by activating PKC. $A$, Numbers of rods present on P1 retinas after $4 \mathrm{~d}$ of culture in the presence of $50 \mathrm{ng} / \mathrm{ml} \mathrm{IGF1,} 100 \mathrm{~nm}$ FGF2, $100 \mathrm{~nm}$ EGF, $100 \mathrm{~nm} \mathrm{BDNF}$, or $100 \mathrm{~nm}$ PMA. Counts were obtained by averaging the number of rods present in three individual histological cross-sections of each retina. At least three different retinas were studied per treatment focusing on the central areas of the retina. $\boldsymbol{B}$, Immunofluorescence detection of opsin (green) overlaid with nuclear counterstain (Hoechst, blue) of $4 \mathrm{dP1}$ retinal explants. P1 retinas were cultured from WT mice for $4 \mathrm{~d}$ in the presence of $50 \mathrm{ng} / \mathrm{ml}$ IGF1 or $100 \mathrm{~nm}$ PMA. OL, Outer retinal layer; IL, Inner retinal layer. C, $\boldsymbol{D}$, Numbers of rods present at the end of a $4 \mathrm{~d}$ culture of P1 WT retinas in the presence of $50 \mathrm{ng} / \mathrm{ml} \mathrm{IGF1} \mathrm{(C),} 100 \mathrm{nM}$ PMA (D), or $100 \mathrm{nM} \mathrm{G07874}(\boldsymbol{C}, \boldsymbol{D}) .{ }^{*} p<0.05,{ }^{* * *} p<0.0001$. Error bars indicate SEM.

specificity. Ret-P1 monoclonal antibody recognizes an epitope on the N terminus of opsin of rod photoreceptors (Barnstable, 1980; Hicks and Barnstable, 1987). Recombinant Leukemia Inhibitory Factor (LIF) was purchased from Millipore; recombinant mouse IGF1 from Sigma; phorbol ester 12-myristate 13-acetate (PMA) from LC Laboratories; Akt inhibitor VIII, Go7874, and PKC- $\beta$ inhibitor from Calbiochem; PI3K inhibitor (Ly294002) from Cell Signaling Technology; and FGF2, EGF, and BDNF from BioSource International.

Animals. C57BL/6J and PKC- $\gamma$ knock-out (KO; B6;129P2-

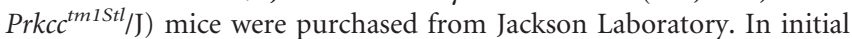
experiments, we noticed small differences in the timing of rod development between the $\mathrm{C} 57 \mathrm{BL} / 6 \mathrm{~J}$ strain and the B6;129P2-Prkcc ${ }^{t m 1 S t l} / \mathrm{J}$ strain. To eliminate these genetic background differences, we backcrossed the $\mathrm{KO}$ animals to $\mathrm{C} 57 \mathrm{BL} / 6 \mathrm{~J}$ and heterozygous animals mated to generate homozygous PKC- $\gamma \mathrm{KO}$, wild-type (WT), and heterozygous littermates. All experiments were approved by the Animal Care and Use Committee of Pennsylvania State University School of Medicine. Mice were housed on a $12 \mathrm{~h}$ light/dark cycle with ad libitum access to rodent chow. Embryonic day 15.5 (E15.5), E17.5, P1, P3, P5, P7 and P13 animals of either sex were used for tissue sectioning and immunohistochemistry.

P1 animals of either sex were used for retinal explant cultures. Most of the litters were born on E20, which was considered equivalent to P1. Embryos were dissected into cooled PBS for retinal explant isolation. Genotyping of the PKC- $\gamma \mathrm{KO}$ animals was performed using the following primers and Jackson Laboratory protocols: wild-type oIMR0496, GCT CCG ACG AAC TCT ATG CCA; oIMR0497, GTG GAG TGA AGC TGC GTG AGA; mutant generic neoprimers, oIMR6916, CTT GGG TGG AGA GGC TAT TC; oIMR6917, AGG TGA GAT GAC AGG AGA TC.

Retina isolation and culture. Whole retinas were isolated from pups at $\mathrm{P} 1$, by removing the sclera and most of the retinal pigmented epithelium layer (Sparrow et al., 1990; Zhao and Barnstable, 1996; Zhang et al., 2002, 2004), and cultured in UltraCulture (CambrexBio Science) serum-free medium supplemented with gentamycin antibiotic $(10 \mu \mathrm{g} / \mathrm{ml})$. Retinas were culture individually in $1 \mathrm{ml}$ of medium in a 24 -well culture dish at $37^{\circ} \mathrm{C}$ in a $5 \% \mathrm{CO}_{2}$ (balance air) atmosphere. The medium was changed every other day by replacing $0.5 \mathrm{ml}$ with fresh medium.

Dissociated retinal cells were obtained by incubating isolated retinas in $0.25 \%$ trypsin at $37^{\circ} \mathrm{C}$ for $15 \mathrm{~min}$. Retinas were transferred to tubes containing DMEM with $10 \%$ FBS. A flame-polished glass Pasteur pipette was used to triturate the retinas to obtain single cells. Cells were then placed on a glass slide coated with poly-L-lysine (Sigma) and fixed in $4 \%$ PFA for $30 \mathrm{~min}$. Cells were subsequently double labeled for PCNA (1:5000) and for PKC- $\beta$ I (1:1000), PKC- $\gamma(1: 1000)$, or STAT3 (1:1000).

Western blot. Whole-cell extracts were prepared and Western blot assays performed as described previously (Asao and Fu, 2000; Zhang et al., 2004). Briefly, retinas from postnatal mice or explanted retinas were suspended in a whole-cell extract buffer. The tissues were frozen and thawed three times to lyse the cells. The supernatant was collected by microcentrifugation, and protein concentrations were measured. Lysate ( 25 to $30 \mu \mathrm{g}$ ) was separated by SDS-PAGE and transferred to ImmunBlotTM polyvinylidene difluoride membrane (Bio-Rad). After blocking with 5\% nonfat milk in washing buffer, membranes were incubated with primary antibodies. Following washes, they were incubated in antirabbit or anti-mouse IgG coupled to horseradish peroxidase. The immunoreactive bands were visualized using SuperSignalR chemiluminescent substrate (Thermo Scientific). The quantitative image analysis was performed using Image J 1.29 (http://rsb.info.nih.gov/ij/).

Histology and immunocytochemistry. Whole eyes and explanted retinas were fixed with $4 \%$ paraformaldehyde in PBS for $24 \mathrm{~h}$ at $4^{\circ} \mathrm{C}$. After three washes with PBS, fixed explants were dehydrated through a series of graded ethanols and embedded in paraffin. All samples for one experiment were placed in the same blocks and sectioned for immunohistochemistry. Antigen retrieval was performed by using $6.5 \mathrm{~mm}$ sodium citrate, $\mathrm{pH}$ 6, and boiling for $45 \mathrm{~min}$. A standard immunohistochemistry protocol (Zhang et al., 2003, 2004) was used for single or double labeling using fluorescent dye-conjugated secondary antibodies (Jackson ImmunoResearch). Sections were imaged using an Olympus Fluoview FV1000 confocal microscope. For each set of experiments, acquisition parameters for each antibody were held constant.

Sections used for cell counting were taken adjacent to the optic nerve and contained the full extent of the retina from central to peripheral regions. Labeled rods were counted over the full length of retina and normalized for variations in tissue size. No correction was made for retinal thickness as all were close to $70 \mu \mathrm{m}$. Cell counts were obtained for three sections from each retina, and at least three retinas were studied per treatment. 
Real-time reverse transcriptase-PCR. Total RNA was isolated by TRIzol (Invitrogen) and purified by RNeasy mini kits (Qiagen). Final concentrations were determined spectrophotometrically using a GeneSpect III (Hitachi). For each sample, $50 \mu \mathrm{l}$ of reverse transcriptase (RT) reaction containing $2 \mu \mathrm{g}$ of RNA, $10 \mu \mathrm{l}$ of $5 \times$ first-strand buffer, $5 \mu \mathrm{l}$ of $10 \mathrm{~mm}$ deoxyribonucleotide triphosphates, $5 \mu \mathrm{l}$ of $0.1 \mathrm{~mm}$ dithiothreitol, $1 \mu \mathrm{l}$ of RNase-OUT, and $1 \mu \mathrm{l}$ of SuperScript II reverse transcriptase (Invitrogen) was incubated at $42^{\circ} \mathrm{C}$ for $50 \mathrm{~min}$.

Real-time PCR used a $25 \mu \mathrm{l}$ reaction volume containing $12.5 \mu \mathrm{l}$ of Sybr-green supermix (Bio-Rad) with primers and $12.5 \mu \mathrm{l}$ of diluted RT product. Annealing temperatures were set at $60^{\circ} \mathrm{C}$ for 40 cycles using an iCycler (Bio-Rad). Primer sequences were as follows: opsin, forward, 5' -TGC TGT TTT CCT TGG CCT TTG G-3'; reverse, 5' -TCT CTT CAG CAT GCC AGG AAG T-3'; $\beta$-actin, forward, $5^{\prime}$-GTG GGG CGC CCC AGG CAC CA-3'; reverse, $5^{\prime}$-CTCCTT ATT GTC ACG CAC GGA TTT C-3'; Crx, forward, 5' -TCA AGA ACC GGA GGG CTA AAT-3'; reverse, 5'-ATA GCT CTG GCC TGA TAG GGA.

Statistical analysis. Statistical analyses were performed using the GraphPad Prism software. Student's $t$ test (two-tailed, unpaired) was used to compare two groups, and one-way ANOVA (with NewmanKeuls post test) was used to compare more than two groups.

\section{Results}

\section{PKC regulates appearance of rod photoreceptors in retinal} explant cultures

To test whether intrinsic signals from peptide growth factors or neurotrophins could stimulate the generation of rod photoreceptors, we added IGF1, FGF2, EGF, or BDNF for $4 \mathrm{~d}$ to P1 retinal explant cultures. We also tested the action of a phorbol ester, a molecule known to affect differentiation in many cell types. After $4 \mathrm{~d}$ in culture, retinas were fixed and labeled with an opsin antibody to count the number of rod photoreceptors. Approximately 50 rods per section $(49.8 \pm 5.5 ; n=5)$ were detected in sections from control tissues. BDNF treatment led to only a slight increase $(66.67 \pm 8.8 ; n=3 ; p=0.15)$ in the number of rods counted. Both EGF and FGF2 increased the number of rods present at the end of the culture $(n=3 ; 86.7 \pm 10.1, p<0.02$ and $88.0 \pm 7.6$, $p<0.01$, respectively), but IGF1 $(182.2 \pm 5.9 ; n=5 ; p<0.0001)$ and PMA $(170.6 \pm 3.4 ; n=5 ; p<0.0001)$ both caused a much greater increase (Fig. $1 A, B$ ). Because of the smaller effects of EGF and FGF2, we did not pursue the mechanism of action of these factors further.

A major action of PMA is the activation of PKCs. We tested whether the increase in opsin-positive cells induced by PMA, and by IGF1, might be due to activation of PKC by repeating the experiments in the presence Go7874, a pan inhibitor of PKCs. Such cultures did not show any significant increase in opsinpositive cells over control (Fig. $1 C, D$ ). These results suggest that activation of PKC, either chemically or by the growth factor IGF1, can increase the production of opsin-positive rod photoreceptors in the neonatal mouse retina.

To ensure that the changes brought by PKC activation were on the whole process of rod photoreceptor differentiation rather than just on opsin expression, we examined the expression of the transcription factor Crx, another early marker of rods. After $4 \mathrm{~d}$ in culture, we found that activation of PKC by PMA and IGF1 increased expression of Crx RNA over eightfold $(n=4 ; 8.6 \pm 5.3$, $p<0.02$ and $9.8 \pm 2.2, p<0.007$, respectively), an increase comparable to that of opsin itself $(n=4 ; 5.2 \pm 2.4, p<0.02$ and $7.2 \pm 1.2, p<0.005$ ) (Fig. $2 A, B)$. Similarly, treatment with either IGF1 or PMA increased opsin and Crx protein levels by approximately twofold $(n=3 ; 1.6 \pm 0.2, p<0.05$ and $1.9 \pm 0.05, p<$ 0.05 , respectively) (Fig. $2 C, D$ ). These results suggest that activation of one or more isoforms of PKC is sufficient to trigger ex-
A

Opsin

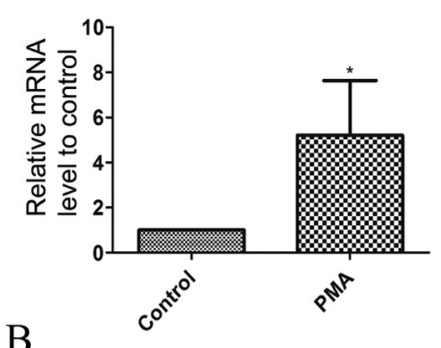

B

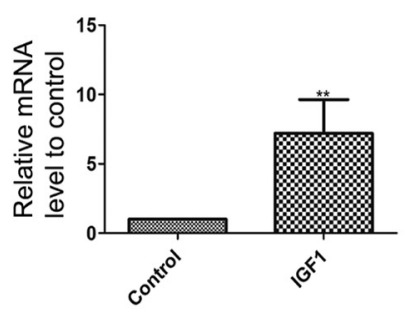

C

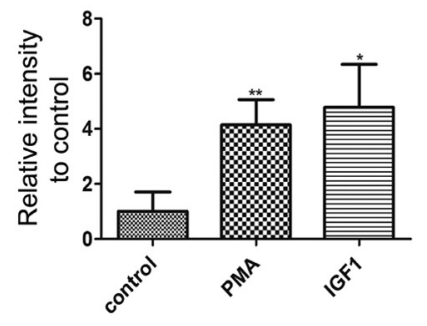

$\mathrm{D}$

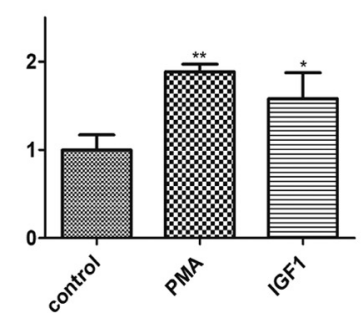

Figure 2. IGF1 and PMA treatment of P1 retinal explants increases expression of rod specific genes. $A, B$, Quantitative RT-PCR assay showing expression of opsin and Crx in P1 retinal explants cultured for $4 \mathrm{~d}$ in the presence of PMA $(\boldsymbol{A})$ or IGF1 $(\boldsymbol{B}) .{ }^{*} p<0.05$; ${ }^{* *} p<0.005$. Beta-actin and GAPDH expression was used to normalize mRNA levels and values are expressed relative to control levels. $\boldsymbol{C}, \boldsymbol{D}$, Amount of opsin $(\boldsymbol{C})$ and $\mathrm{Crx}(\boldsymbol{D})$ proteins found in $4 \mathrm{~d}$ retinal explants of $\mathrm{P} 1$ retinas using Western blot analysis. Beta-actin expression was used to normalize total protein levels. Values in graph are normalized to control levels. ${ }^{*} p<0.05,{ }^{* *} p<0.01$. Error bars indicate SEM.

pression of multiple genes that are characteristic of the early stages of rod photoreceptor differentiation.

\section{PKC- $\beta \mathrm{I}$ and PKC- $\gamma$ are expressed in dividing progenitors at the time of rod photoreceptor differentiation}

PKC exists as a series of eight classical $(\alpha, \beta \mathrm{I}, \beta \mathrm{II}$, and $\gamma)$ and novel $(\delta, \varepsilon, \eta$, and $\theta)$ isoforms that can be activated by phorbol esters, as well as atypical forms that are not sensitive to these agents. To define which $\mathrm{PKC}$ isoforms might be responsible for inducing rod formation, we first examined the temporospatial pattern of classical and novel PKC isoform expression during retinal development. No expression of $\beta \mathrm{II}, \delta, \varepsilon, \eta$, and $\theta$ isoforms was detected by either immunocytochemistry or Western blotting (data not shown). On the other hand, both PKC- $\gamma$ (Fig. $3 A-D)$ and PKC- $\beta 1(E-H)$ were expressed strongly at the outer margin of the retina from embryonic stages until the end of retinogenesis in the first postnatal week. In addition, both PKC isoforms were expressed by cells in the inner retina, and this expression persisted into adulthood (data not shown). PKC- $\alpha$ was detected only after P5, when the differentiation of most retinal cells is substantially advanced (Fig. $3 I-L$ ). As described previously, it is expressed mainly in the bipolar cells of the inner nuclear layer, suggesting that it has a limited involvement, if any, in rod development (Osborne et al., 1992; Kosaka et al., 1998). 

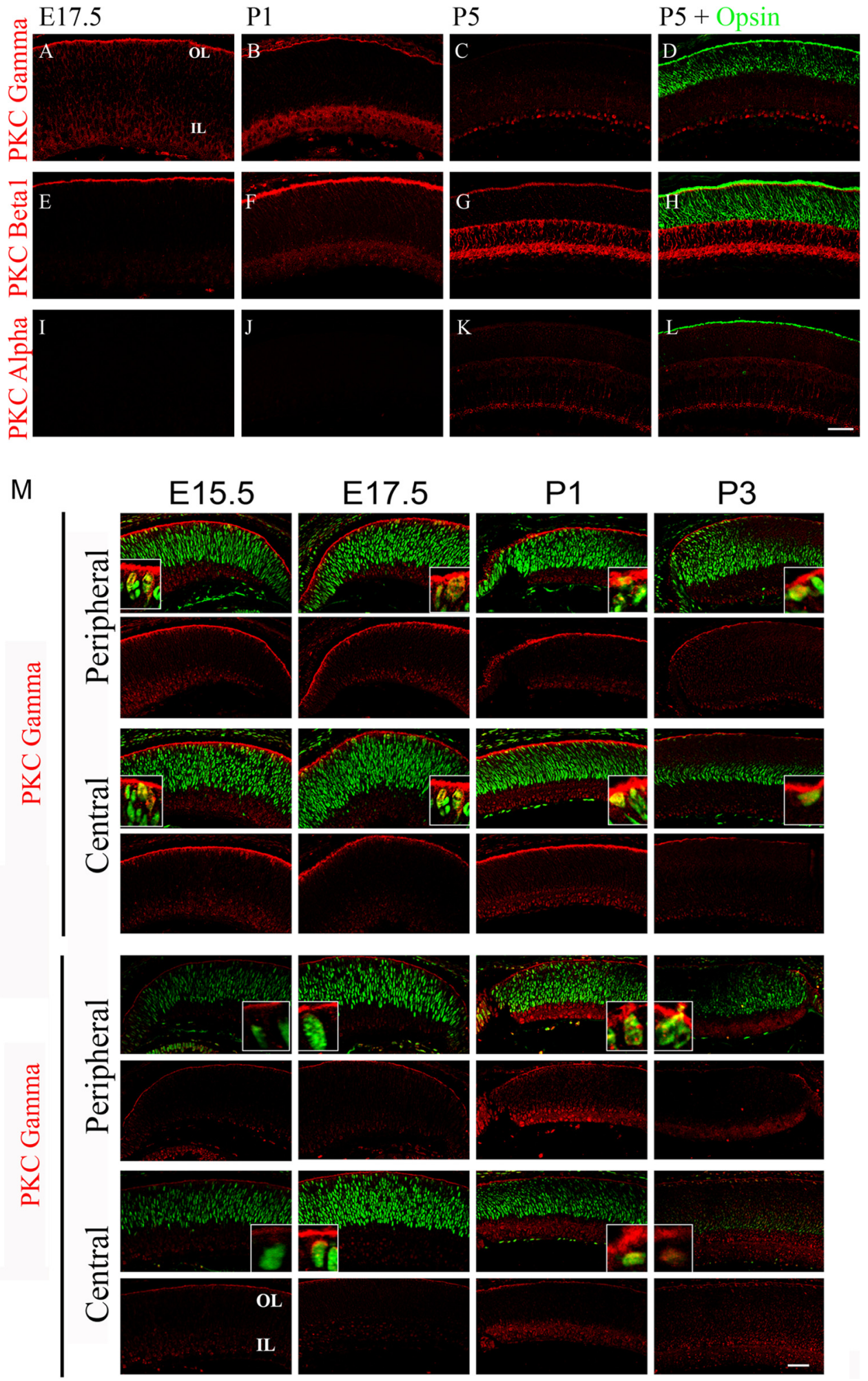

Figure 3. PKC- $\beta 1$ and PKC $\gamma$ isoforms are expressed during retinal development. $\boldsymbol{A}-\boldsymbol{L}$, Immunofluorescent detection of PKC- $\alpha$, PKC $-\beta 1$, and PKC- $\gamma($ red) from E17.5 (A, $\boldsymbol{E}, \boldsymbol{I}), \mathrm{P} 1(\boldsymbol{B}, \boldsymbol{F}, \boldsymbol{J}), \mathrm{P5}$ $(\boldsymbol{C}, \boldsymbol{G}, \boldsymbol{K})$ and colocalization with opsin (green) expression at P5 $(\boldsymbol{D}, \boldsymbol{K}, \boldsymbol{L}) . \boldsymbol{M}$, Expression of PKC $-\beta 1$ and PKC $-\gamma($ red) colocalization with PCNA (green) in the central and peripheral retina of E15.5, $\mathrm{E} 17.5, \mathrm{P} 1$, and P3 retinas. $\mathrm{OL}$, Outer retinal layer; IL, inner retinal layer. Scale bar, $40 \mu \mathrm{m}$.

At early postnatal stages, the outer layer of the retina contains both proliferating progenitors and postmitotic neurons. To test which cell population in this region expressed PKC- $\beta 1$ and PKC- $\gamma$, we costained the sections with PCNA antibody to label the dividing cells. Although much of the PKC- $\beta 1$ and PKC- $\gamma$ labeling was present in the apical processes of retinal cells at the very outer edge of the retina, we found some PKC- $\gamma$ - and PKC$\beta 1$-labeled cell bodies, and these colocalized with PCNA-positive cells in the outer retina during late embryonic and early postnatal stages of retinal development (Fig. 3M). By P3, it became harder to detect dividing cells in central retina, although many were still present in more peripheral regions. Because much of the PKC- $\beta 1$ 
and PKC- $\gamma$ labeling was in the cell processes, particularly the endings at the outer surface, it was difficult to get an accurate estimate of the extent of overlap in labeling. To confirm that PKC was in fact expressed in the mitotic cells, we also stained cells dissociated from E17.5 retinas. A much clearer staining localized to the membrane of the cells was observed with the PKC- $\beta 1$ and PKC- $\gamma$ antibodies. At this stage, $95 \%$ of the cells were PCNA positive, and of these, $83 \%$ were also PKC- $\beta 1$ positive, and $85 \%$ were also PKC- $\gamma$ positive (data not shown). This confirms the expression of these PKC isoforms in progenitor cells and indicates that most of the cells expressed both isoforms.

\section{PKC- $\beta 1$ and PKC- $\gamma$ each have an effect on rod} photoreceptor development

Although both PKC- $\beta 1$ and PKC- $\gamma$ are expressed in dividing progenitors at the time that many of them progress into a rod photoreceptor lineage, the pattern of expression does not show which of these enzymes regulates the normal process of rod photoreceptor development. To investigate whether PKC- $\beta 1$ was capable of enhancing rod photoreceptor development, we pharmacologically inhibited PKC- $\beta$ using a compound developed by Eli Lilly and commercialized by Calbiochem. This PKC inhibitor has $\mathrm{IC}_{50}$ values of $12 \mathrm{~nm}$ for PKC- $\beta 1,5 \mathrm{~nm}$ for PKC- $\beta \mathrm{II}$, and 331 nM for PKC- $\alpha$, and higher than $1 \mu \mathrm{M}$ for PKC- $\gamma$ and PKC- $\varepsilon$. Since this inhibitor is orders of magnitude more effective on PKC- $\beta 1$ and PKC- $\beta$ II, but PKC- $\beta$ II is not expressed in retinas during rod development, we used it as a specific inhibitor of PKC- $\beta 1$ in our retinal explants. Treatment of explants with the PKC- $\beta$ inhibitor (30 nM) plus PMA reduced the number of rods detected compared to treatment with PMA alone (Fig. 4A), although the increase was still twofold greater than untreated controls $(2.1 \pm 0.2 ; n=3 ; p<0.005)$. Even 10-fold higher concentrations of PKC- $\beta$ inhibitor did not further reduce the number of rods, suggesting that the partial reduction was not due to suboptimal concentrations of the inhibitor. As in previous experiments, however, addition of the pan-PKC inhibitor Go7874 reduced the number of detectable rods to control levels.

We repeated these experiments using IGF1 to activate PKC and found that IGF1 treatments increased the number of rods present by almost sixfold $(5.7 \pm 0.4 ; n=3 ; p<0.005)$, and addition of the PKC- $\beta$ inhibitor substantially reduced the increase, although it remained significantly above control values $(2.7 \pm 0.2 ; n=3 ; p<0.005)$. Here again, 10 -fold higher concentrations of PKC- $\beta$ inhibitor did not change the magnitude of this increase, whereas the pan-PKC inhibitor Go7874 reduced the number of rods to control levels (Fig. 4B).

To examine the effects of PKC- $\gamma$ on rod development, we used PKC- $\gamma$ KO mice. We first examined the natural time course of opsin-positive rod appearance using sections of eyes obtained from animals of various ages (Fig. 5). At P5, the PKC- $\gamma$ KO animals did not contain any opsin-positive rod photoreceptors, whereas wild-type littermates already had a substantial number of rods. At P7, the PKC- $\gamma$ KO animals appear to have fewer opsin-positive cells. The fluorescence intensity of equal areas of opsin-stained retinas was reduced by $50 \%$ in PKC- $\gamma$ KO retinas compared to wild-type littermate retinas $(0.4 \pm 0.1 ; n=4 ; p<$ 0.009). By P13, however, retinas from PKC- $\gamma \mathrm{KO}$ animals had no detectable difference in the fluorescence intensity of opsinlabeling photoreceptors, and there were no significant changes in the morphology of the rods at this level of resolution when compared to control littermates (Fig. 5B). This suggests that the absence of PKC- $\gamma$ causes a substantial delay of rod development, but that eventually a full complement of rods is formed. One
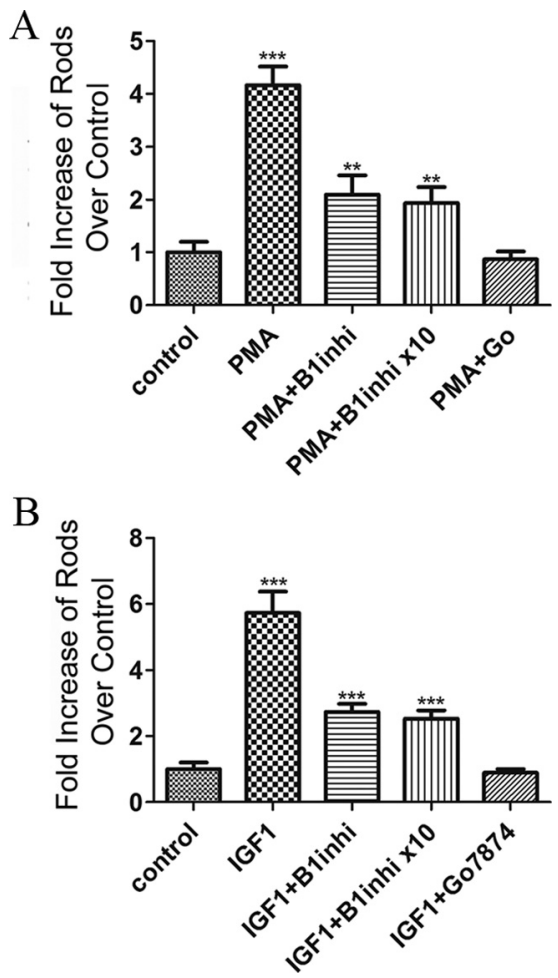

Figure 4. Inhibition of PCK- $\beta 1$ activity partially inhibits the effect of PMA and IGF1 on rod photoreceptor formation. $\boldsymbol{A}, \boldsymbol{B}$, Increase in rods present at the end of a $4 \mathrm{~d}$ culture of $\mathrm{P} 1$ retinas after addition of PMA $(\boldsymbol{A})$ and IGF1 $(\boldsymbol{B})$ in the presence or absence of PCK- $\beta 1$-specific inhibitor (B1inhi; 30 or $300 \mathrm{~nm}$ ) or $100 \mathrm{~nm}$ PKC pan inhibitor (G07874) relative to untreated explants. Values were obtained by averaging the number of rods present in three individual section of a single retina. At least three different retinas were studied per treatment. ${ }^{* *} p<0.005$; ${ }^{* * *} p<$ 0.001. Error bars indicate SEM.

mechanism by which the absence of PKC- $\gamma$ could delay rod differentiation is by retarding the exit of cells from the proliferative pool. To test this idea, we investigated the expression of PCNA in the outer layer of the retina, using the outer plexiform layer as a boundary (Fig. 5C). By measuring fluorescence intensity, we found that at P5, PKC- $\gamma$ KOs contain almost three times as much labeling in the outer layer of the retina as wild-type littermates $(2.8 \pm 0.7 ; n=4 ; p<0.007)$. The difference was even more striking in the outer layers of the retinas of P7 PKC- $\gamma \mathrm{KO}$ animals, where we found almost 13 times more PCNA labeling than in their wild-type littermates $(12.7 \pm 0.7 ; n=4 ; p<0.005)$. This persistence of the progenitor pool was temporary because at P13 neither the PKC- $\gamma$ KO nor the WT littermates had detectable PCNA-positive cells.

To examine whether IGF1, or PMA, could enhance rod photoreceptor differentiation even in the absence of PKC- $\gamma$ and PKC- $\beta 1$ activity, we tested the effects of these agents on the PKC- $\gamma$ KO retinas. As shown in Figure $6 A$, when cultured in the presence PMA for $4 \mathrm{~d}$, PKC- $\gamma$ KO retinas had almost eight times the number of rods compared with PKC- $\gamma$ KO control retinas cultured in medium alone ( $7.5 \pm 0.5 ; n=4 ; p<0.0001)$. Addition of the PKC- $\beta$ inhibitor completely abolished the PMA stimulation and reduced the number of rods to below the levels in untreated cultures $(0.57 \pm 0.11 ; n=4 ; p=0.09)$. Similarly, when the retinas were cultured in the presence of IGF1 (Fig. $6 B$ ), we found that there were approximately nine times more rods than in untreated retinas $(9.2 \pm 0.6 ; n=4 ; p<0.0001)$, but retinas cultured in the presence of IGF1 plus the inhibitor of PKC- $\beta$ had numbers of rods not significantly different from untreated reti- 
A

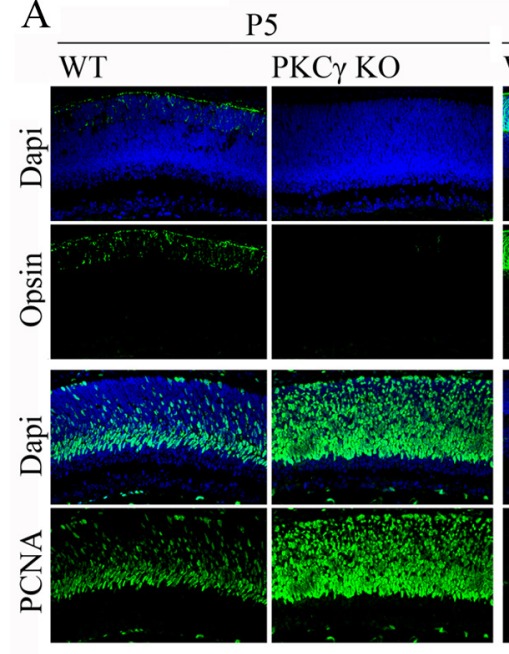

B
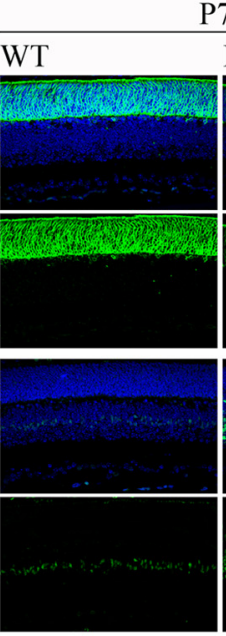

P7
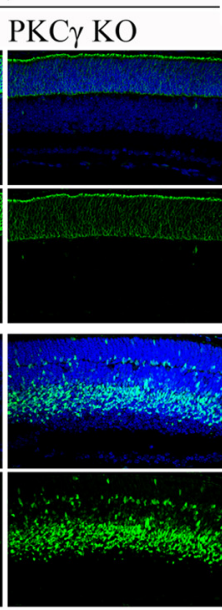

C
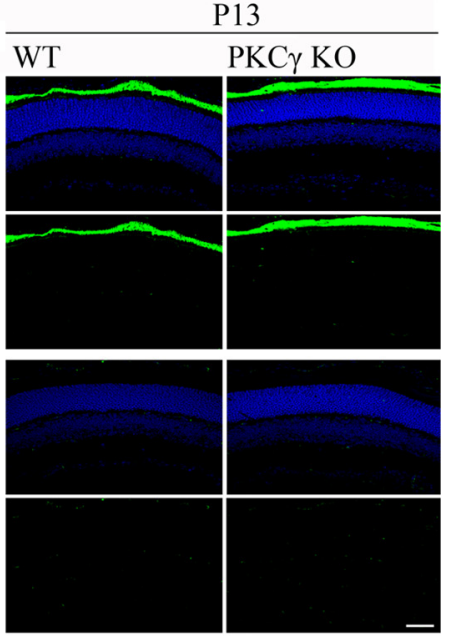
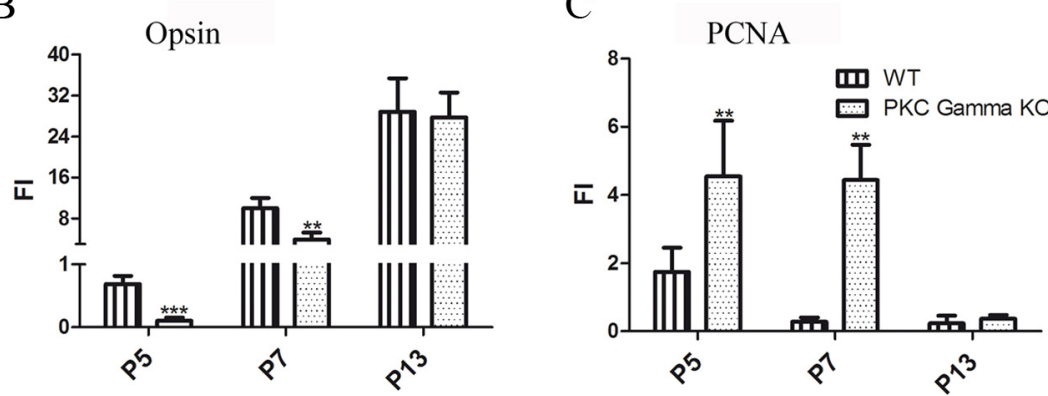

Figure 5. Absence of PKC- $\gamma$ during retinal development causes a delay in rod formation and prolongs progenitor cell cycle exit. $\boldsymbol{A}$, Immunofluorescence detection of opsin and PCNA (green) of PKC- $\gamma$ KO and WT littermate retinas of ages P5, P7, and P13. Sections were overlaid with nuclear counterstain (Hoechst blue). $\boldsymbol{B}$, Fluorescence intensity of opsin present in retinas at ages P5, P7, and P13, comparing PKC- $\gamma$ KO retinas to wild-type littermates. C, Fluorescence intensity of PCNA present in the outer layer of the retinas at ages P5, P7, and P13, comparing PKC- $\gamma$ K0 retinas to wild-type littermates. The outer plexiform layer defined the limit between outer and inner layers of the retina. ${ }^{* *} p<0.01 ;{ }^{* * *} p<0.005$. Values were obtained by averaging the fluorescence intensity of at least three representative areas of at least three different retinas. Scale bar, $40 \mu \mathrm{m}$. Error bars indicate SEM.

nas. This result confirms that the effects of PMA and IGF1 on rod development can be partially mediated through either PKC- $\gamma$ or PKC- $\beta 1$. However, in the absence of PKC- $\gamma$ and PKC- $\beta 1$ activities, by gene targeting and specific pharmacological inhibition, respectively, neither PMA nor IGF1 were able to induce rod formation.

We next tested whether the activity of PKC- $\gamma$ and PKC- $\beta 1$ is necessary for control levels of rod photoreceptor formation in the absence of added factors using P1 retinal explants. To effectively distinguish between a delay in rod development, as seen in PKC- $\gamma \mathrm{KO}$ animals, and a complete block in rod development, we cultured PKC- $\gamma \mathrm{KO}$ and wild-type littermate retinas for $8 \mathrm{~d}$, which is ample time to achieve rod differentiation. We cultured retinas from PKC- $\gamma \mathrm{KO}$ animals and WT littermates in the presence of the specific PKC- $\beta 1$ inhibitor (Fig. $7 A-D$ ) and measured opsin expression by summing the total fluorescence over a uniform field of the section. We found that $\mathrm{PKC}-\gamma \mathrm{KO}$ retinas cultured in the presence of PKC- $\beta 1$ inhibitor contained very few opsin-labeled cells and only $8 \%$ of the total opsin fluorescence found in the WT littermates (Fig. 7E). We conclude that in the absence if both PKC- $\gamma$ and PKC- $\beta 1$, normal rod development is halted.

IGF1 fails to activate PI3K in $\mathrm{P} 1$ retinas

To investigate the pathway by which IGF1 activates PKC during development, we looked at the role of the major enzymes regulated by IGF1 receptor activity, namely, PI3K and its downstream target Akt. Addition of the pan Akt inhibitor VIII to P1 retinal explants for $4 \mathrm{~d}$ did not result in any significant change in the number of rods in control conditions, or the increased number of rods seen following IGF1 treatment (Fig. $8 \mathrm{~A}$ ). This suggests that the effects of IGF1 on rod development were not dependent on Akt activity.

On the other hand, when cultures were treated with the compound Ly294002 to inhibit the activity of PI3K, the number of rods was over nine times that of control cultures $(9.4 \pm 0.2 ; n=$ 3 ; $p<0.0001$ ) (Fig. 8B). Adding IGF1 together with Ly294002 did not substantially increase the number of rods over that induced by the inhibitor alone $(10.1 \pm 0.2 ; n=3 ; p<0.0001)$ (Fig. $8 B$ ). The effects of PI3K inhibitor on rod development were PKC dependent since the stimulatory effect of adding Ly294002 to the PKC- $\gamma$ KO retinal cultures was blocked by the PKC- $\beta$ inhibitor (Fig. 8C).

Thus, both IGF1 and PI3K inhibitor treatments increase the number of rod photoreceptors. This seems paradoxical since in many cell types IGF1 stimulates the activity of PI3K and subsequent Akt phosphorylation. Since our results were more compatible with an inhibition of PI3K mediated by IGF1, we compared the actions of IGF1 on freshly isolated neonatal and adult retinas by measuring the phosphorylation of downstream targets of PI3K 5 and 30 min after the addition of IGF1. As shown in Figure 9, in adult retinas IGF1 treatments resulted in increase phosphorylation of Akt with a maximum stimulation at 5 min that was approximately three times compared to control $(3.3 \pm 0.6 ; n=3$; $p<0.05)$. The stimulation gradually decreased after $30 \mathrm{~min}$ exposure to IGF1 $(1.703 \pm 0.1602 ; n=6 ; p<0.005)$, a result in 

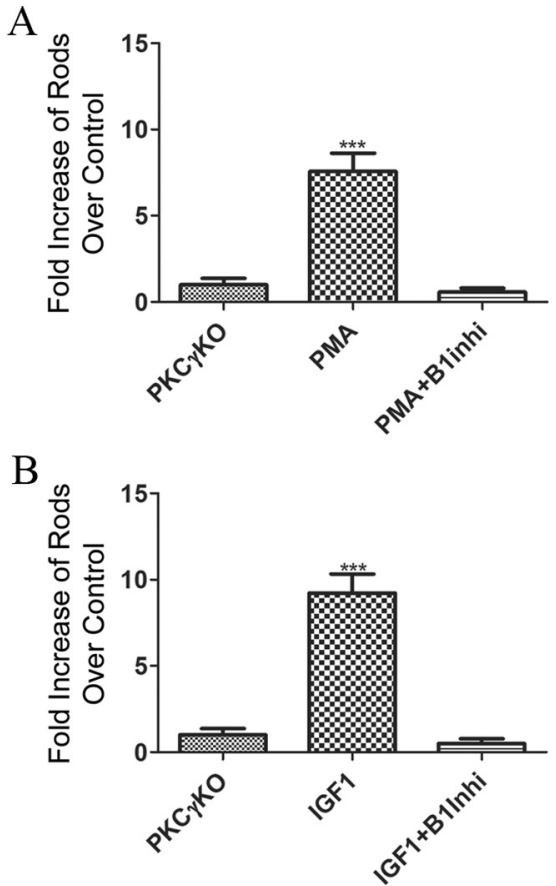

Figure 6. In the absence of PKC- $\beta 1$ or PKC- $\gamma$, neither PMA nor IGF1 can induce rod photoreceptor formation. $A$, Increase in rods present at the end of a $4 \mathrm{~d}$ culture of P1 PKC $-\gamma$ KO retinas in the presence of $100 \mathrm{~nm}$ of PMA and PMA plus $30 \mathrm{~nm}$ PKC- $\beta 1$ inhibitor relative to untreated explants. $\boldsymbol{B}$, Increase in rods present at the end of a $4 \mathrm{~d}$ culture of PKC $-\gamma$ KO retinas in the presence of $50 \mathrm{ng} / \mathrm{ml}$ IGF1 or IGF1 and $30 \mathrm{~nm}$ PKC- $\beta 1$ inhibitor. Cell counts were obtained from four retinas for each treatment. Error bars indicate SEM.

accord with other studies (Barber et al., 2001; Biswas et al., 2008). In the neonatal retinas, however, IGF1 treatment led to a significant reduction in phosphorylation of Akt to $15 \%$ of control after 5 min of treatment $(0.2 \pm 0.1 ; n=3 ; p<0.003)$ and $50 \%$ of control after $30 \min (0.5 \pm 0.03 ; n=7 ; p<0.001)$.

To confirm the effects of IGF1 on the PI3K/Akt pathway, we looked at the phosphorylation of GSK3 $\beta$ on Ser 9, which is mediated by Akt upon stimulation of PI3K. We found a reduction of $\sim 20 \%$ on the phosphorylation of GSK3 $\beta$ after a 5 min addition of IGF1 $(0.8 \pm 0.04 ; n=3 ; p<0.005)$, confirming the inhibitory effects of IGF1 on the PI3K/Akt pathway in the neonatal retina (Fig. 9B). On the other hand, treatment of adult retinas for 5 min with IGF1 resulted in increased phosphorylation of GSK $3 \beta$ by $\sim 75 \%$ compared to untreated retinas $(1.7 \pm 0.08 ; n=3 ; p<0.05)$.

To distinguish whether the different response to IGF1 in neonatal tissue was due to IGF receptor dysfunction or to a change at the postreceptor level, we examined the effects of IGF1 on another IGF1 receptor-coupled pathway, the ERK/MAPK pathway. As shown in Figure $9 C$, in the adult retinas, treatment with IGF1 for 5 min resulted in $70 \%$ increase on the Tyr204 phosphorylation of ERK $(1.7 \pm 0.2 ; n=3 ; p<0.05)$. In the neonatal retinas, ERK phosphorylation increased by almost fivefold $(5.0 \pm 1.0$; $n=3 ; p<0.05$ ), suggesting the tyrosine kinase activity of the IGF1 receptor is active throughout development in the retina and that the effects we observe are due to altered structure or activity of the PI3K enzyme itself or its coupling to the receptor.

\section{IGF1 does not phosphorylate the regulatory domain of PI3K in $\mathrm{P} 1$ retinas}

To evaluate the mechanism behind the different effects of IGF1 treatments in adult and P1 retinas on PI3K activity, we looked at

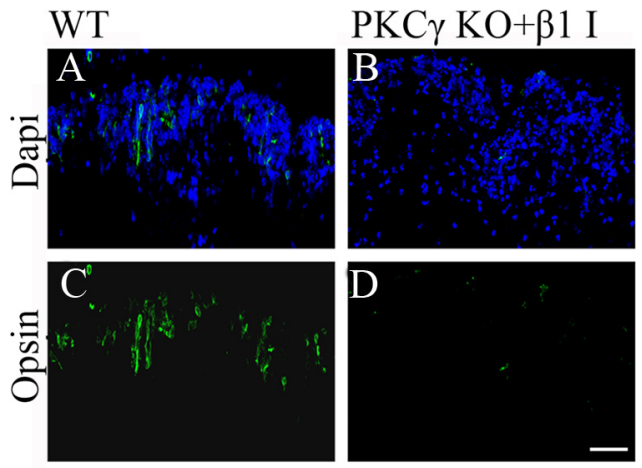

$\mathrm{E}$

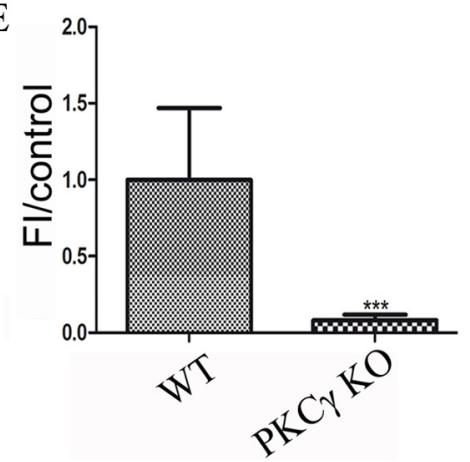

Figure 7. Absence of PKC- $\beta 1$ and PKC $-\gamma$ isoforms during retinal development inhibits rod photoreceptor formation. $\boldsymbol{A}-\boldsymbol{D}$, Immunofluorescence detection of opsin (green) in P1 retinas after $8 \mathrm{~d}$ culture of PKC $-\gamma$ KO and WT littermates in the presence of PKC- $\beta 1$ inhibitor. Sections were overlaid with nuclear counterstain (Hoechst blue). $\boldsymbol{E}$, Fluorescence intensity of rhodopsin present in P1 retinas after $8 \mathrm{~d}$ culture of PKC $-\gamma$ KO and WT littermates in the presence of PKC- $\beta 1$ inhibitor. ${ }^{* * *} p<0.009$. Values were obtained by averaging the fluorescence intensity of at least three representative areas of at least three retinas. Scale bar, $40 \mu \mathrm{m}$. Error bars indicate SEM.

the expression of catalytic and regulatory domains of PI3K in P1 and adult retinas. We found that both adult and P1 retinas express the $\mathrm{P} 110 \alpha$ catalytic domain and the $\mathrm{p} 85$ regulatory domain, and there was no detectable change in total protein in $\mathrm{P} 1$ retinas after IGF1 treatment (data not shown). We also investigated the effects of IGF1 on the phosphorylation of the regulatory domain of PI3K using an antibody specific for $\mathrm{p} 85$ tyrosine phosphorylation at residue 458 . We found that 5 min stimulation with IGF1 did not result in phosphorylation of p85 in either P1 or adult retinas. The same antibody, however, recognizes the tyrosine phosphorylation of p55 splice variant at residue 199, and we found that adult retinas contained a substantial amount of phosphorylated p55, and IGF1 treatment for 5 min resulted in 50\% increase in phosphorylation of p55 $(1.5 \pm 0.1 ; n=3 ; p<0.05)$ (Fig. 10). However, we did not detect any phosphorylation of $\mathrm{p} 55$ either before or after IGF1 treatment in P1 retinas. The absence of phosphorylation of the regulatory domain after 5 min treatment with IGF1 in P1 retinas may be responsible for the differences in phosphorylation state of Akt between adult and P1 retinas.

\section{IGF1 inhibits STAT3 tyrosine phosphorylation}

Activation of STAT3 during retinal development inhibits differentiation of rod photoreceptors. We therefore tested the hypothesis that IGF1 increased the number of rod photoreceptors by inhibiting STAT3 tyrosine phosphorylation.

We preincubated P1 retinal explants in medium for $5 \mathrm{~h}$ and then treated them with PMA or IGF1 for $30 \mathrm{~min}$. We analyzed the levels of tyrosine phosphorylation of STAT3 by Western blots (Fig. 11A). Treatment with PMA or IGF1 decreased the levels of 


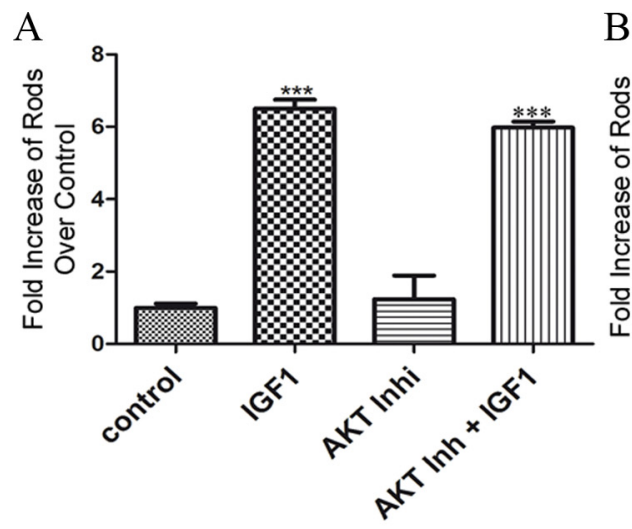

$\mathrm{D}$
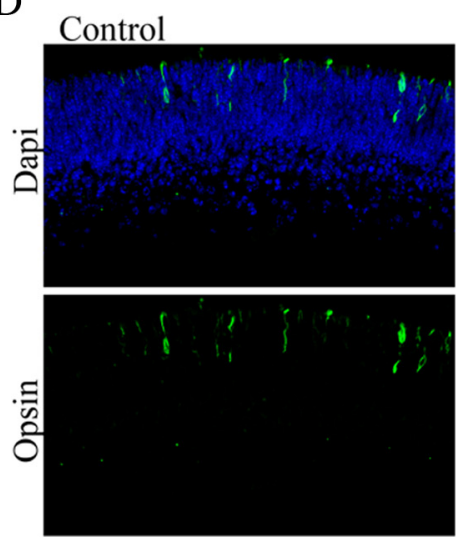

PI3K Inhibitor
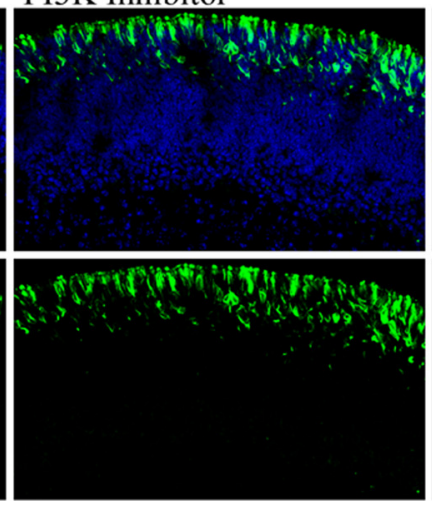

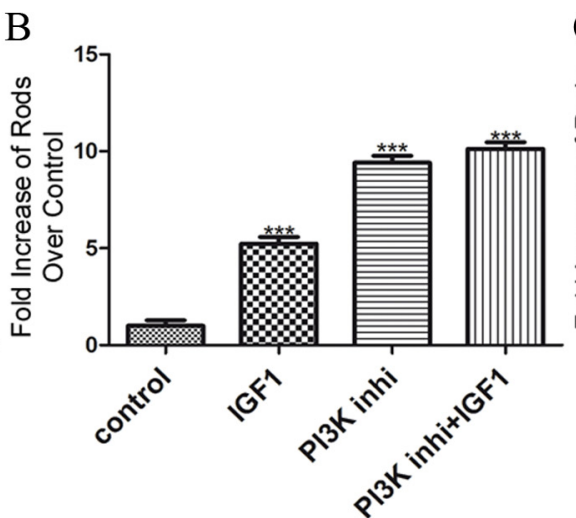

B1 Inhibitor

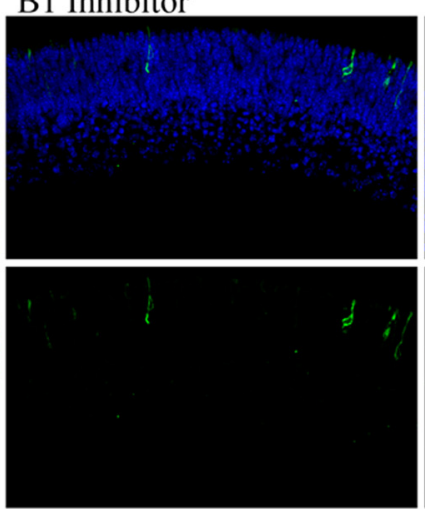

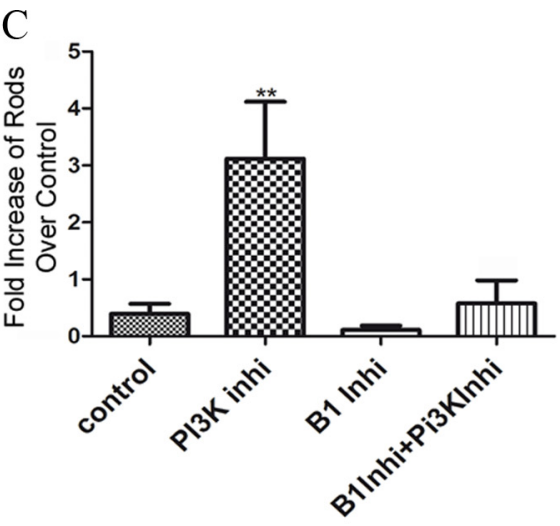

B1 Inhi + PI3K Inhi

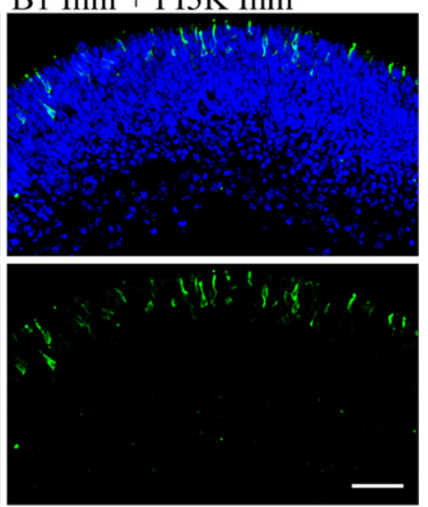

Figure 8. IGF1 activates PKC by inhibiting PI3K activity. A, Number of rods found in P1 WT retinas at the end of a $4 \mathrm{~d}$ culture in the presence of $50 \mathrm{ng} / \mathrm{ml}$ IGF1 and $500 \mathrm{~nm}$ Akt inhibitor VIII. $\boldsymbol{B}$, Number

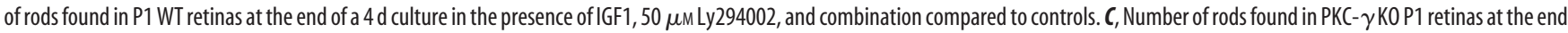
of a $4 \mathrm{~d}$ culture in the presence of Ly294002, PCK- $\beta 1$ inhibitor, and a combination of the two expressed as a ratio to the number in untreated controls. Total number of rods was counted from at least three cross sections of a single treated retina. At least three retinas were studied, and the average was plotted. ${ }^{* *} p<0.01$; ${ }^{* * *} p<0.001$. D, Immunofluorescence detection of opsin (green) in PKC $-\gamma$ KO P1 retinas after $4 \mathrm{~d}$ of culture in the presence of $50 \mu \mathrm{m}$ Ly294002, $30 \mathrm{~nm}$ PCK- $\beta 1$ inhibitor, and a combination. Scale bar, $40 \mu \mathrm{m}$. Error bars indicate SEM.
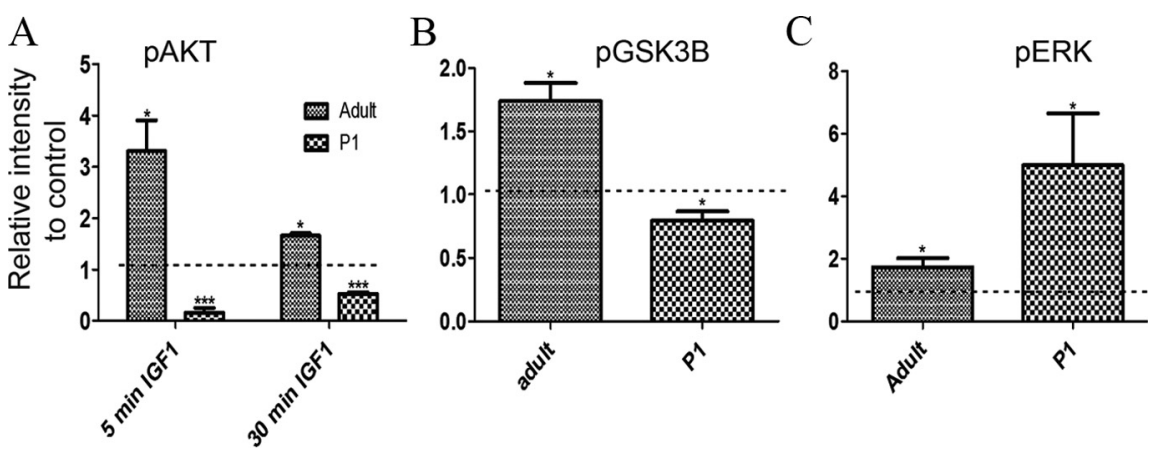

Figure 9. IGF1 treatment of $P 1$ and adult retinas results in opposite effects on phosphorylation of Akt and GSK3 $\beta$. A, Amount of phosphorylated Ser 473 Akt found in adult and P1 WT retinas after 5 and 30 min treatment with $50 \mathrm{ng} / \mathrm{ml} \mathrm{IGF1.} \mathrm{B,} \mathrm{Amount} \mathrm{of}$ phosphorylated Ser 9 GSK3 $\beta$ found in adult and P1 WT retinas after 5 min treatment with $50 \mathrm{ng} / \mathrm{ml}$ IGF1. C, Amount of phosphorylated Tyr 204 ERK found in adult and P1 WT retinas after 5 min treatment with $50 \mathrm{ng} / \mathrm{ml} \mathrm{IGF1.}{ }^{*} p<0.05$; ${ }^{* * *} p<0.005$ versus control. Dotted lines depict the levels of untreated retinas. At least three retinas were studied per condition. Error bars indicate SEM.

tyrosine phosphorylation of STAT3 relative to untreated controls by 70 and $80 \%$, respectively $(0.3 \pm 0.1, n=6, p<0.001$ and $0.3 \pm$ $0.1, n=3, p<0.002$, respectively). However, simultaneous addition of Go7874 not only abolished the effects of IGF1 and PMA, but the levels of phosphorylation of STAT3 were higher than control levels with IGF1 $(2.9 \pm 0.4 ; n=3 ; p<0.002)$ and similar to control levels with the PMA. These data suggest that IGF1 and PMA can regulate the tyrosine phosphorylation levels of STAT3 through modulation of PKC activity, and that PKC activity plays an important role in determining the baseline level of STAT3 activity.
We obtained similar results when we treated the retinas with the PI3K inhibitor Ly294002. A 30 min treatment with Ly294002 decreased the tyrosine phosphorylation of STAT3 by $50 \%$ ( $0.5 \pm 0.05$; $n=3 ; p<0.002)$, a reduction that was also abolished by the simultaneous addition of 100 nM Go7874.

A prediction from these results is that the absence of PKC- $\beta 1$ and PKC- $\gamma$ would lead to increased baseline pSTAT3 levels. Retinas were isolated from P1 PKC- $\gamma \mathrm{KO}$ and WT littermates and cultured for $5 \mathrm{~h}$, and the protein was extracted and analyzed for the levels of phosphorylated STAT3. We found that the basal levels of phosphorylated STAT3 in the PKC- $\gamma \mathrm{KO}$ animals were significantly greater than those in the WT littermates $(2.7 \pm 0.55 ; n=3 ; p<0.05)$ (Fig. $11 B)$. In addition, when PKC- $\beta 1$ inhibitor was added to the culture for the entire $5 \mathrm{~h}$, phosphorylation of STAT3 was further increased to almost five times the levels of control WT untreated retinas $(5.0 \pm 1.0 ; n=3 ; p<0.005)$. STAT3 can promote its own expression through a STAT3 binding site in its promoter (Narimatsu et al., 2001). When we examined the effects of inhibition of PKC- $\gamma$ on total STAT3 protein, we found that PKC- $\gamma \mathrm{KO}$ had almost twice as much STAT3 total protein as the WT littermate 
A

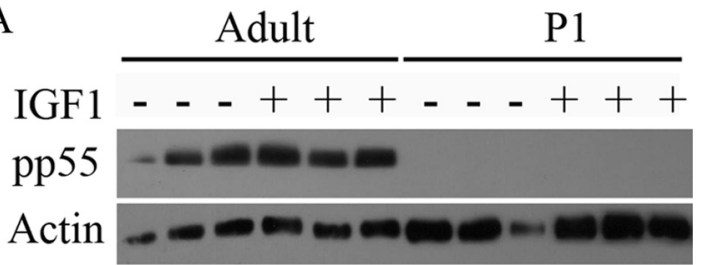

B

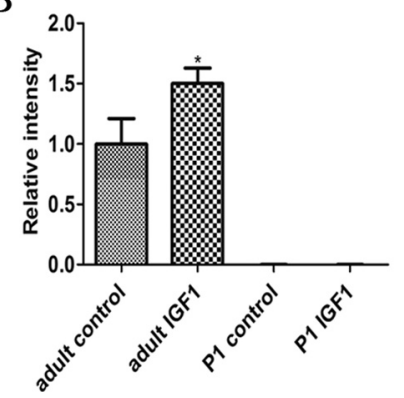

Figure 10. In P1 retinas, IGF1 does not phosphorylate the regulatory domain of PI3K. $A$, Western blot with phosphorylated p55 in P1 and adult retinas under control conditions and after 5 min treatment with IGF1. B, Histogram of normalized band intensities of pp55. ${ }^{*} p<$ 0.05 versus control. At least three retinas were studied per condition. Error bars indicate SEM.

control (1.9 $\pm 0.06 ; n=3 ; p<0.005)$ (Fig. 11C). When we added the PKC- $\beta$ inhibitor to the PKC- $\gamma$ KO retinas, the total levels of STAT3 did not increase further. In addition, WT retinas in the presence of PKC- $\beta$ inhibitor on average total levels of STAT3 increased $\sim 50 \%$, but the changes did not reach statistical significance.

To test whether PKC activation could also prevent LIFinduced STAT3 tyrosine phosphorylation, we added IGF1 or PMA to cultures at the same time as LIF or for a $3 \mathrm{~h}$ preincubation. Although simultaneous addition of IGF1 or PMA was not able to reduce the increase in STAT3 phosphorylation, a $3 \mathrm{~h}$ preincubation significantly reduced the effect of LIF without any significant effect on STAT3 protein levels (Fig. 11D,E). These data suggest that PMA and IGF1 can prevent the activation of STAT3 by LIF, which has been shown previously to inhibit rod differentiation (Zhang et al., 2004).

This effect is also apparent at the cellular level since preincubation with PMA for $6 \mathrm{~h}$ was able to block LIF-induced inhibition of rod photoreceptor development (Fig. 12) and increased the number of rods present at the end of the culture by over fivefold when compare to untreated controls $(5.2 \pm 0.7 ; n=9 ; p<0.0001)$.

Together, these experiments demonstrate that activation of PKC- $\beta 1$ and PKC- $\gamma$ by growth factors such as IGF1 or agents such as PMA can reduce STAT3 activation and release the block on the transition from progenitor cell to differentiating rod photoreceptor.

\section{Discussion}

In this paper, we have shown that specific isoforms of PKC are pivotal intracellular mediators of signals that regulate the production of rod photoreceptors in the postnatal mouse retina. The complete lack of rods detected in the presence of PKC inhibitors suggests that this enzyme may play this key role for the wide variety of other signals that can elicit rod production.

To provide access to factors that might modulate rod photoreceptor formation, we made use of a well-characterized explant culture system that we developed and have used in many studies of retinal development (Sparrow et al., 1990; Zhao et al., 1995;
Zhang et al. 2002, 2004, 2005). These cultures maintain excellent cell viability, tissue lamination, and cell differentiation. In a microarray analysis of gene expression in vivo and in explant cultures, we did, however, find that expression of some genes is delayed by $1-2 \mathrm{~d}$ (Liu et al., 2008). This is apparent in the low levels of opsin expression in $4 \mathrm{~d}$ explant cultures from P1 animals compared with sections from P5 animals. Nevertheless, since $>75 \%$ of 8880 expressed genes detected in retinal explants showed the same expression volume and pattern as in vivo, we feel that the cultures are an excellent model of retinal development.

Of the 11 known isozymes of PKC, we found only two, PKC- $\beta 1$ and PKC- $\gamma$, that were expressed in retinal progenitor cells between E17.5 and P5, the peak of rod differentiation, to control rod development. Specific inhibition of either isoform reduced the number of rods formed following stimulation by either IGF1 or direct chemical stimulation by PMA, but completion blockade of rod formation was only achieved when the activity of both isoforms was blocked. Since both isoforms were coexpressed in many of the progenitor cells, this suggests redundancy of function rather than expression in separate cell populations. Further work, however, may reveal additional functions unique to each isoform, or additional signal mechanisms that selectively activate one or the other. A similar developmental role for PKC- $\beta 1$ and PKC- $\gamma$ has been suggested by several studies in other regions of the CNS. In spinal cord, PKC- $\alpha$, PKC- $\beta 1$, and PKC- $\gamma$ are expressed in developing motor neurons, and it has been suggested that they are necessary for various aspects of both morphological and functional differentiation of these cells (Miki, 1996). Similarly, tissue culture studies have implicated PKC- $\beta 1$ and PKC- $\gamma$ in differentiation of astrocytes and oligodendrocytes (Asotra and Macklin, 1994).

Although we do not know the immediate targets of PKC- $\beta 1$ and PKC- $\gamma$, we propose that a key action of these enzymes is to regulate the activity of STAT3. There is growing evidence that STAT3 plays a pivotal role in mammalian development. It serves as a key transcription factor regulating mouse embryonic stem cell self-renewal, and in the embryonic neocortex, STAT3 activity maintains neural precursor cells (Yoshimatsu et al., 2006; Xie et al., 2009). Our previous results had indicated that STAT3 has this role throughout development since it serves as a gatekeeper to determine whether retinal progenitor cells remain in a proliferating pool or transition into a terminal differentiation pathway. Sustained activation of STAT3 by virally encoded, constitutively active STAT3 completely blocked rod photoreceptor formation and, conversely, a virally encoded dominant-negative form of STAT3 allowed formation of rods even in the presence of CNTF (Zhang et al., 2004). A variety of signals found in the developing retina can promote STAT3 activity, including Notch-Delta-like 1, FGF1, IFN- $\alpha$, and LIF, and the maintenance of a progenitor state is presumably due to the sum of their activity (Zhang et al., 2004; 2005; Yoshimatsu et al., 2006). Some of these signals decrease with developmental age, suggesting that the driving force for STAT3 activation declines as progenitor cells become competent to differentiate. Our results suggest that PKC has an active role in regulating the decrease in STAT3 activation necessary to trigger rod photoreceptor differentiation.

Two known mechanisms of STAT3 inactivation are inhibition of Janus kinase by SOCS3 and by increased activation of phosphatases. SOCS3 is expressed in the outer retina and is upregulated when STAT3 is downregulated (Ozawa et al., 2004). SOCS3 is clearly activated by posttranscriptional mechanisms, and it is possible that these are the substrate for PKCs action. Because cells contain a substantial number of phos- 
A
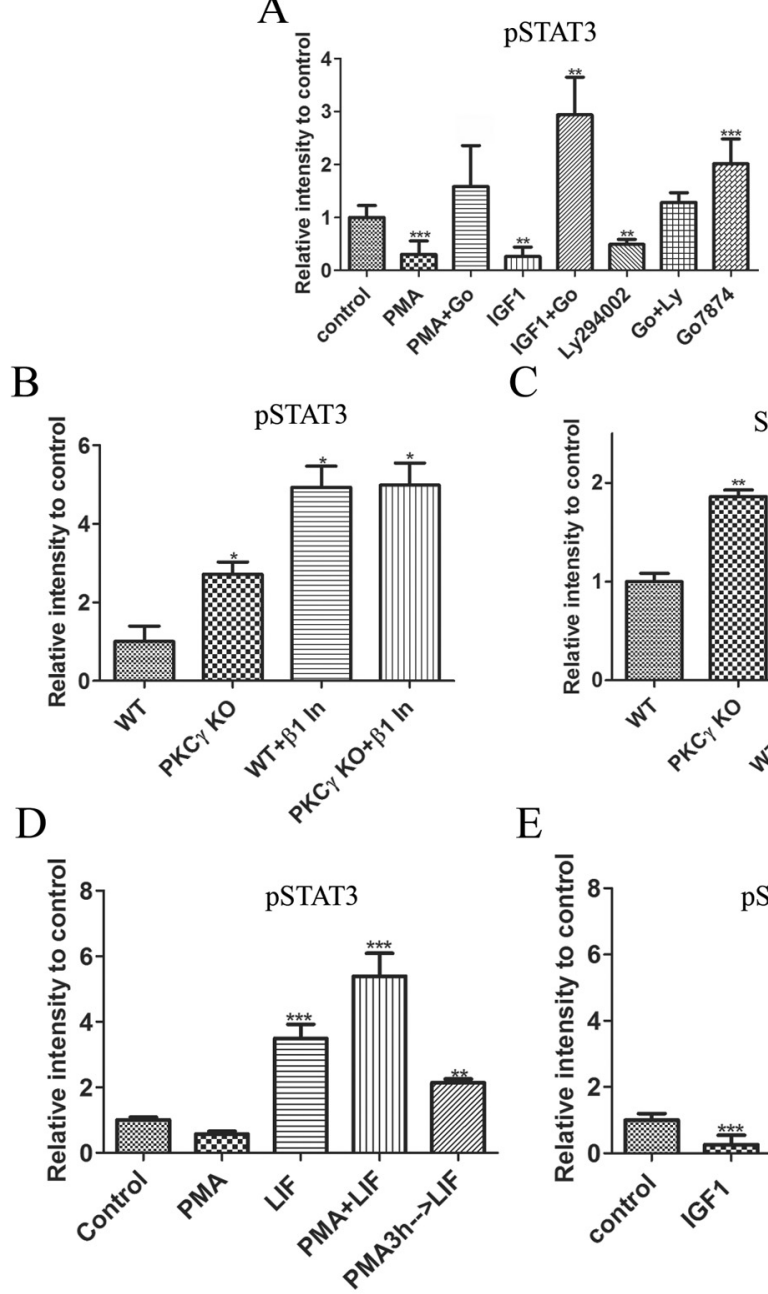

$\mathrm{C}$
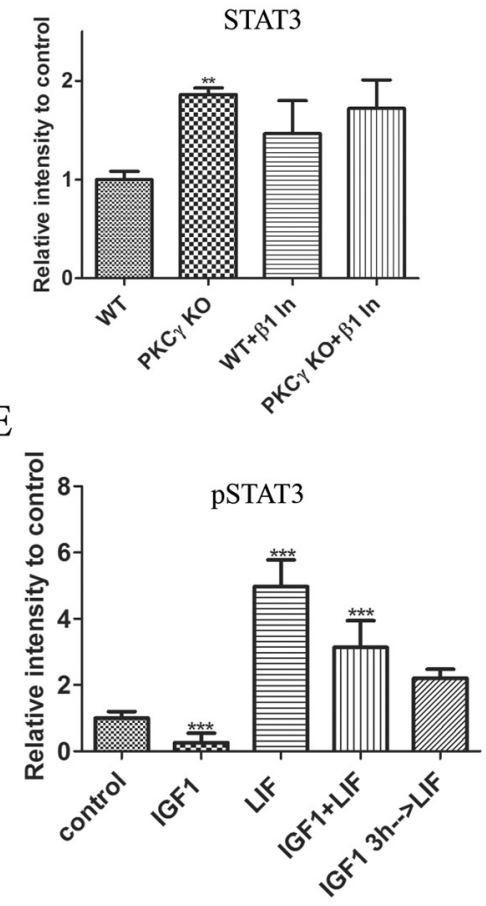

Figure 11. PKC activation inhibits LIF-induced STAT3 tyrosine phosphorylation. A, Amount of tyrosine-phosphorylated STAT3 found in P1 WT retinas after 5 h explant culture followed by 30 min treatment with $100 \mathrm{~nm} \mathrm{PMA,} 50 \mathrm{ng} / \mathrm{ml}$ IGF1, $100 \mathrm{~nm}$ Go 7874, and $50 \mu \mathrm{m}$ Ly294002. B, C, Amount of tyrosine phosphorylated STAT3 ( $\boldsymbol{B}$ ) and total STAT3 ( $\boldsymbol{C}$ ) found in retinas of P1 PKC $-\gamma$ KO and WT littermates cultured for $5 \mathrm{~h}$ in the presence or absence of PCK- $\beta 1$ inhibitor. $\boldsymbol{D}, \boldsymbol{E}$, Amount of tyrosine-phosphorylated STAT 3 found in P1 WT retinas after $5 \mathrm{~h}$ explant culture followed by $3 \mathrm{~h}$ preincubation with either PMA (D) or IGF1 (E) with subsequent addition of LIF for 30 min. ${ }^{*} p<0.05 ;{ }^{* *} p<0.005 ;{ }^{* * *} p<0.0005$. Error bars indicate SEM.

phatases, and the signal cascade from IGF1 to STAT3 involves multiple steps of phosphorylation, it is currently difficult to determine whether PKC- $\beta 1$ and PKC- $\gamma$ exert their effects on STAT3 through activation of a phosphatase.

Perhaps the most surprising result reported here is that IGF1 and an inhibitor of the IGF1 receptor both increase the number of rods in retinal explants. In the retina, IGF1 levels increase postnatally from $<200 \mathrm{pg} / \mathrm{mg}$ at birth to $300 \mathrm{pg} / \mathrm{mg}$ at P7, and $>400$ $\mathrm{pg} / \mathrm{mg}$ at P21 (Modanlou et al., 2006), a time course consistent with a role for IGF1 as an extracellular signal that triggers rod formation. A number of studies have implicated IGF1 in neural development, although many of these studies have focused on the role of this factor in proliferation and survival of cells (HernándezSánchez et al., 1995; Meyer-Franke et al., 1995; Kermer et al., 2000; Morimoto et al., 2005).

The IGF1 receptor regulates ERK phosphorylation through a Ras/Raf pathway (Webster et al., 1994; Keeton et al., 2005; Kiepe et al., 2005; Parrizas et al., 1997), and the increase in ERK1/2 phosphorylation induced by IGF1 indicates that its receptor was activated in both neonatal and adult retinas. In many cell types,

the major effect of IGF1 is activation of PI-3 kinase, a result we confirmed in mature retinal tissue. On the other hand, in the P1 retinas, IGF1 treatment led to a decrease in phosphorylation of both Akt and GSK $3 \beta$. This suggests that the coupling between the IGF1 receptor and the enzyme PI-3 kinase is abnormal in the neonate. In support of this is our finding that in the adult but not P1 retinas, IGF1 induces an increase in the phosphorylation of the p55 regulatory subunit of PI-3 kinase. Phosphorylation of the regulatory subunit by the activated IGF1 receptor is essential for PI-3 kinase activation. At present we do not know whether there is a difference in regulatory subunit expression at the different ages or a failure of the p55 subunit to interact with the receptor in the P1 tissue. This, however, is only a partial explanation of our results. The level of phosphorylation (activation) of Akt is a balance set by the relative levels of activators produced by PI-3 kinase and the actions of inhibitory phosphatases, such as SHIP2 and pharbin (Clement et al., 2001; Wada et al., 2001; Pesesse et al., 1997; Ishihara et al., 1999; Sasaoka et al., 2004). We propose that IGF1 binding to its receptor in P1 tissue activates one of these phosphatases, which is not counteracted by PI3K, resulting in a net effect of reduced phosphorylated Akt. Since Akt itself is not involved in stimulating formation of rods, we propose that the same imbalance results in the activation of PKC- $\beta 1$ and PKC- $\gamma$.

A similar mechanism may be responsible for the induction of rods seen with the PI3K inhibitor (Ly294002) treatment. In the retina, many growth factors activate PI3K upon binding to its receptors, including PDGF, BDNF, EGF, and bFGF (Nakazawa et al., 2002; Hollborn et al., 2004; Biswas et al., 2008). The receptor activation simultaneously stimulates other proteins such as MAPK and phosphatases that feed back and balance each other's activities. Addition of the PI3K inhibitor unbalances the signaling of all the receptors that may be activating PI3K at that time; thus, the stimulation of rod production is even higher. It is therefore the lack of activity of PI3K that directly or indirectly allows PKC to promote rod photoreceptor differentiation.

Although we have described our results as a single pathway, it is clear that the key step, activation of PKC- $\beta 1$ and PKC- $\gamma$, can be regulated by multiple pathways (for review, see Ananthanarayanan et al., 2003). It is possible that many of the factors that have been shown to influence rod formation in the developing retina converge at this step of PKC activation and that the level of activation is the sum of multiple pathways. Since many of these factors change their level of expression as a consequence of the development of other retinal cells or other systemic events, this provides a mechanism for the retina to generate rod photoreceptors in synchrony with development of the whole organism. 

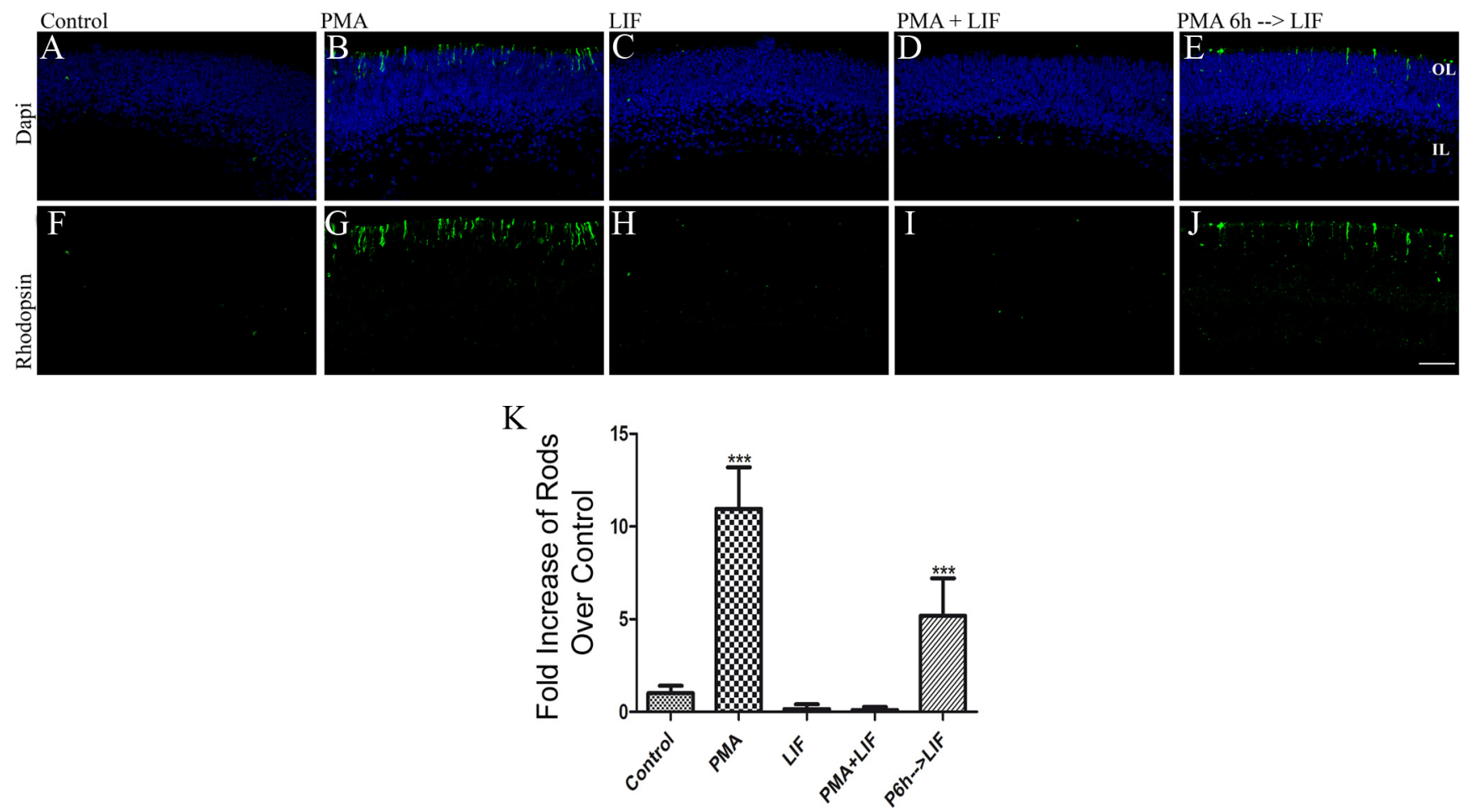

Figure 12. PMA preincubation abolishes LIF-induced block of rod photoreceptor development. $A-J$, Immunofluorescence detection of rhodopsin (green) in WT P1 retinas after $4 \mathrm{~d}$ of culture in the presence of $100 \mathrm{~nm} P M A(B, G), 20 \mathrm{ng} / \mathrm{ml}$ of LIF $(\boldsymbol{C}, \boldsymbol{H})$, PMA and LIF added at the same time $(\boldsymbol{D}, \boldsymbol{I})$, and $6 \mathrm{~h}$ pretreatment with PMA followed by LIF $(\boldsymbol{E}, J)$. $\boldsymbol{K}, \boldsymbol{G r a p h}$ of the number of rods present at the end of a $4 \mathrm{~d}$ culture of WT P1 retinas in the presence of PMA, LIF, and a combination. ${ }^{* * *} p<0.005$. Scale bar, $40 \mu \mathrm{m}$.

\section{References}

Altshuler D, Cepko C (1992) A temporally regulated, diffusible activity is required for rod photoreceptor development in vitro. Development 114:947-957.

Altshuler D, Lo Turco JJ, Rush J, Cepko C (1993) Taurine promotes the differentiation of a vertebrate retinal cell type in vitro. Development 119:1317-1328.

Ananthanarayanan B, Stahelin RV, Digman MA, Cho W (2003) Activation mechanisms of conventional protein kinase $\mathrm{C}$ isoforms are determined by the ligand affinity and conformational flexibility of their C1 domains. J Biol Chem 278:46886-46894.

Asao H, Fu XY (2000) Interferon-gamma has dual potentials in inhibiting or promoting cell proliferation. J Biol Chem 275:867-874.

Asotra K, Macklin WB (1994) Developmental expression of protein kinase $\mathrm{C}$ isozymes in oligodendrocytes and their differential modulation by 4 beta-phorbol-12,13-dibutyrate. J Neurosci Res 39:273-289.

Barber AJ, Nakamura M, Wolpert EB, Reiter CE, Seigel GM, Antonetti DA, Gardner TW (2001) Insulin rescues retinal neurons from apoptosis by a phosphatidylinositol 3-kinase/Akt-mediated mechanism that reduces the activation of caspase-3. J Biol Chem 276:32814-32821.

Barnstable CJ (1980) Monoclonal antibodies which recognize different cell types in the rat retina. Nature 286:231-235.

Biswas SK, Zhao, Nagalingam YA, Gardner TW, Sandirasegarane L (2008) PDGF- and insulin/IGF1-specific distinct modes of class IA PI 3-kinase activation in normal rat retinas and RGC-5 retinal ganglion cells. Invest Ophthalmol Vis Sci 49:3687-3698.

Clement S, Krause U, Desmedt F, Tanti JF, Behrends J, Pesesse X, Sasaki T, Penninger J, Doherty M, Malaisse W, Dumont JE, Le Marchand-Brustel Y, Erneux C, Hue L, Schurmans S (2001) The lipid phosphatase SHIP2 controls insulin sensitivity Nature 409:92-97.

Hernández-Sánchez C, López-Carranza A, Alarcón C, de la Rosa EJ, de Pablo F (1995) Autocrine/paracrine role of insulin-related growth factors in neurogenesis: local expression and effects on cell proliferation and differentiation in retina. Proc Natl Acad Sci U S A 92:9834-9838.

Hicks D, Barnstable CJ (1987) Different rhodopsin monoclonal antibodies reveal different binding patterns on developing and adult rat retina. J Histochem Cytochem 35:1317-1328.

Hollborn M, Jahn K, Limb GA, Kohen L, Wiedemann P, Bringmann A
(2004) Characterization of the basic fibroblast growth factor-evoked proliferation of the human Muller cell line, MIO-M1. Graefes Arch Clin Exp Ophthalmol 242:414-422.

Holt CE, Bertsch TW, Ellis HM, Harris WA (1988) Cellular determination in the Xenopus retina is independent of lineage and birth date. Neuron $1: 15-26$.

Ishihara H, Sasaoka T, Hori H, Wada T, Hirai H, Haruta T, Langlois WJ, Kobayashi M (1999) Molecular cloning of rat SH2-containing inositol phosphatase 2 (SHIP2) and its role in the regulation of insulin signaling. Biochem Biophys Res Commun 260:265-272.

Keeton AB, Bortoff KD, Franklin JL, Messina JL (2005) Blockade of rapid versus prolonged extracellularly regulated kinase $1 / 2$ activation has differential effects on insulin-induced gene expression. Endocrinology 146:2716-2725.

Kermer P, Klöcker N, Labes M, Bähr M (2000) Insulin-like growth factor-1 protects axotomized rat retinal ganglion cells from secondary death via PI3-K-dependent Akt phosphorylation and inhibition of caspase-3 in vivo. J Neurosci 20:2-8.

Kheifets V, Mochly-Rosen D (2007) Insight into intra- and inter-molecular interactions of PKC: design of specific modulators of kinase function. Pharmacol Res 55:467-476.

Kiepe D, Ciarmatori S, Hoeflich A, Wolf E, Tonshoff B (2005) Insulin-like growth factor (IGF)-I stimulates cell proliferation and induces IGF binding protein (IGFBP)-3 and IGFBP-5 gene expression in cultured growth plate chondrocytes via distinct signaling pathways. Endocrinology 146:3096-3104

Kosaka J, Suzuki A, Morii E, Nomura S (1998) Differential localization and expression of alpha and beta isoenzymes of protein kinase $\mathrm{C}$ in the rat retina. J Neurosci Res 54:655-663.

Levine EM, Close J, Fero M, Ostrovsky A, Reh TA (2000) p27Kip1 regulates cell cycle withdrawal of late multipotent progenitor cells in the mammalian retina. Dev Biol 219:299-314.

Liu MG, Xu X, Zhang SSM, Barnstable CJ (2008) Comparison of gene expression during in vivo and in vitro retina development. J Ocul Biol Dis Infor 1:59-72.

Mellor H, Parker PJ (1998) The extended protein kinase C superfamily. Biochem J 332:281-292.

Meyer-Franke A, Kaplan MR, Pfrieger FW, Barres BA (1995) Characteriza- 
tion of the signaling interactions that promote the survival and growth of developing retinal ganglion cells in culture. Neuron 15:805-819.

Miki A (1996) Expression of alpha-, beta-, and gamma-subspecies of protein kinase $\mathrm{C}$ in the motor neurons in the embryonic and postnatal rat spinal cord. Neuroscience 72:805-814.

Modanlou HD, Gharraee Z, Hasan J, Waltzman J, Nageotte S, Beharry KD (2006) Ontogeny of VEGF, IGF-I, and GH in neonatal rat serum, vitreous fluid, and retina from birth to weaning. Invest Ophthalmol Vis Sci 47:738-744.

Morimoto T, Miyoshi T, Matsuda S, Tano Y, Fujikado T, Fujikado Y (2005) Transcorneal electrical stimulation rescues axotomized retinal ganglion cells by activating endogenous retinal IGF1 system. Invest Ophthalmol Vis Sci 6:2147-2155.

Nakazawa T, Tamai M, Mori N (2002) Brain-derived neurotrophic factor prevents axotomized retinal ganglion cell death through MAPK and PI3K signaling pathways. Invest Ophthalmol Vis Sci 43:3319-3326.

Narimatsu M, Maeda H, Itoh S, Atsumi T, Ohtani T, Nishida K, Itoh M, Kamimura D, Park SJ, Mizuno K, Miyazaki J, Hibi M, Ishihara K, Nakajima K, Hirano T (2001) Tissue specific autoregulation of the stat 3 gene and its role in interleukin-6-induced survival signals in T cells. Mol Cell Biol 21:6615-6625.

Oehrlein SA, Maelicke A, Herget T (1998) Expression of protein kinase C gene family members is temporally and spatially regulated during neural development in vitro. Eur J Cell Biol 77:323-337.

Osborne NN, Barnett NL, Morris NJ, Huang FL (1992) The occurrence of three isoenzymes of protein kinase $\mathrm{C}$ (alpha, beta and gamma) in retinas of different species. Brain Res 570:161-166.

Ozawa Y, Nakao K, Shimazaki T, Takeda J, Akira S, Ishihara K, Hirano T, Oguchi Y, Okano H (2004) Downregulation of STAT3 activation is required for presumptive rod photoreceptor cells to differentiate in the postnatal retina. Mol Cell Neurosci 262:258-270.

Parrizas M, Saltiel AR, LeRoith D (1997) Insulin-like growth factor 1 inhibits apoptosis using the phosphatidylinositol 3 '-kinase and mitogenactivated protein kinase pathways. J Biol Chem 272:154-161.

Pesesse X, Deleu S, De Smedt F, Drayer L, Erneux C (1997) Identification of a second SH2-domain-containing protein closely related to the phosphatidylinositol polyphosphate 5-phosphatase SHIP. Biochem Biophys Res Commun 239:697-700.

Rapaport DH, Wong LL, Wood ED, Yasamura D, LaVail MM (2004) Timing and topography of cell genesis in the rat retina. J Comp Neurol 474:304-324.

Reh TA (1992) Cellular interactions determine neuronal phenotypes in rodent retinal cultures. J Neurobiol 23:1067-1083.

Rhee KD, Goureau O, Chen S, Yang XJ (2004) Cytokine-induced activation of signal transducer and activator of transcription in photoreceptor precursors regulates rod differentiation in the developing mouse retina. J Neurosci 24:9779-9788.

Sasaoka T, Wada T, Fukui K, Murakami S, Ishihara H, Suzuki R, Tobe K, Kadowaki T, Kobayashi M (2004) SH2-containing inositol phosphatase 2 predominantly regulates Akt2, and not Akt1, phosphorylation at the plasma membrane in response to insulin in 3T3-L1 adipocytes. J Biol Chem 15:14835-14843.

Sparrow JR, Hicks D, Barnstable CJ (1990) Cell commitment and differentiation in explants of embryonic rat neural retina. Comparison with the developmental potential of dissociated retina. Dev Brain Res 51:69-84.

Turner DL, Cepko CL (1987) A common progenitor for neurons and glia persists in rat retina late in development. Nature 328:131-136.

Wada T, Sasaoka T, Funaki M, Hori H, Murakami S, Ishiki M, Haruta T, Asano T, Ogawa W, Ishihara H, Kobayashi M (2001) Overexpression of SH2-containing inositol phosphatase 2 results in negative regulation of insulin-induced metabolic actions in 3T3-L1 adipocytes via its 5' phosphatase catalytic activity. Mol Cell Biol 21:1633-1646.

Watanabe T, Raff MC (1990) Rod photoreceptor development in vitro: intrinsic properties of proliferating neuroepithelial cells change as development proceeds in the rat retina. Neuron 4:461-467.

Watanabe T, Raff MC (1992) Diffusible rod-promoting signals in the developing rat retina. Development 114:899-906.

Webster J, Prager D, Melmed S (1994) Insulin-like growth factor-1 activation of extracellular signal-related kinase- 1 and -2 in growth hormonesecreting cells. Mol Endocrinol 8:539-544.

Wetts R, Fraser SE (1988) Multipotent precursors can give rise to all major cell types of the frog retina. Science 239:1142-1145.

Xie X, Chan KS, Cao F, Huang M, Li Z, Lee A, Weissman IL, Wu JC (2009) Imaging of STAT3 signaling pathway during mouse embryonic stem cell differentiation. Stem Cells Dev 18:205-214.

Yang XJ (2004) Roles of cell-extrinsic growth factors in vertebrate eye pattern formation and retinogenesis. Seminars in cell and developmental biology 15:91-103.

Yoshimatsu T, Kawaguchi D, Oishi K, Takeda K, Akira S, Masuyama N, Gotoh Y (2006) Non-cell-autonomous action of STAT3 in maintenance of neural precursor cells in the mouse neocortex. Development 133:2553-2563.

Young RW (1985) Cell proliferation during postnatal development of the retina in the mouse. Brain Res 353:229-239.

Zhang SS, Wei J, Qin H, Zhang L, Xie B, Hui P, Deisseroth A, Barnstable CJ, Fu XY (2004) STAT3-mediated signaling in the determination of rod photoreceptor cell fate in mouse retina. Invest Ophthalmol Vis Sci 45:2407-2412.

Zhang SS, Fu XY, Barnstable CJ (2002) Tissue culture studies of retinal development. Methods 28:439-447.

Zhang SS, Wei JY, Li C, Barnstable CJ, Fu XY (2003) Expression and activation of STAT proteins during mouse retina development. Exp Eye Res 76:421-431.

Zhang S, Liu MG, Kano A. Zhan C, Fu XY, Barnstable CJ (2005) STAT3 activation in response to growth factors or cytokines participates in retina precursor proliferation. Exp Eye Res 81:103-115.

Zhao S, Barnstable CJ (1996) Differential effects of bFGF on development of the rat retina. Brain Res 723:169-176.

Zhao S, Thornquist SC, Barnstable CJ (1995) In vitro transdifferentiation of embryonic rat retinal pigment epithelium to neural retina. Brain Res 677:300-310. 